\title{
Modeling the Relationship Between European Carbon Permits and Certified Emission Reductions ${ }^{1}$
}

\author{
Gary Koop, Department of Economics \\ University of Strathclyde \\ $\&$ \\ Lise Tole, Department of Economics \\ University of Strathclyde
}

April 2012, revised August 2013

\begin{abstract}
Recent years have seen an expansion of carbon markets around the world as various policymakers attempt to reduce $\mathrm{CO} 2$ emissions. This paper considers two of the major types of carbon permits: European Union Allowances (EUAs, arising from the European Union Emissions Trading Scheme, EU ETS) and certified emissions reductions (CERs, arising from agreements made under the Kyoto Protocol). The rules of the EU ETS allow for some use of CERs in place of EUAs by EU firms, but this substitutability is only partial. Allowing for carbon permits from different sources to substitute for one another should help achieve $\mathrm{CO} 2$ emissions reductions at least cost. Understanding the degree and nature of linkages (if any) between the markets for EUAs and CER is, thus, an important policy issue. In this paper, we jointly model the spot and future prices of an EUA along with the price of a CER using flexible multivariate time series methods which allow for time-variation in parameters. We find evidence of contemporaneous causality between these three variables with the EUA futures price playing the dominant role in driving this relationship. We also document time-variation in this relationship which is associated with macroeconomic events such as the financial crisis of late 2008 and early 2009. We find very little evidence of volatility spillovers or of Granger causality among any of the variables. We discuss how these empirical findings are consistent with markets which are loosely linked, but are not tightly linked as would be found for perfectly substitutable assets in efficient financial markets.
\end{abstract}

Keywords: carbon trading, spot and futures markets, time-varying parameter VAR, stochastic volatility

JEL Classification Codes: C11, C32, C58, G12, G17, Q54

\footnotetext{
${ }^{1}$ Financial support from the ESRC under grant RES-062-23-2646 is gratefully acknowledged. Both authors are Fellows at the Rimini Centre for Economic Analysis.
} 


\section{Introduction}

The European Union Emissions Trading Scheme (EU ETS) is a cap and trade scheme in which firms in the EU are allocated carbon permits to cover their $\mathrm{CO} 2$ emissions. These carbon permits are known as EUAs (European Union Allowances). ${ }^{2}$ EUAs can be traded so that firms which exceed their CO2 allocations can purchase more of them to cover their excess emissions. Firms with more permits than $\mathrm{CO} 2$ emissions are free to sell their excess permits. A number of financial exchanges have been established in recent years to trade carbon permits and associated financial derivatives. Carbon offsets are also traded in financial markets. Offset markets have arisen as an alternative way of obtaining carbon permits. A firm may offset some of its carbon emissions ${ }^{3}$ by investing in emission reductions elsewhere in the world. The main form of carbon offset is called a CER (certified emission reduction).

The goal of the EU ETS and carbon offset markets is to achieve CO2 reductions in an economically efficient manner. The existence of efficient financial markets for trading carbon permits is necessary to achieve this goal. The purpose of the present paper is to investigate the spot and futures markets for EUAs and their relationship with the market for CERs. These carbon markets are relatively new and have specific institutional features that set them apart from conventional financial markets. For instance, unlike conventional assets, the markets for EUAs exist due to the need for firms to comply with EU regulations, which have been changing over time. Problems have arisen in the EU ETS due to the overallocation of permits to individual firms and fraud of various sorts. Furthermore, there is uncertainty over the future form of the EU ETS. Similar concerns hold with the CER market. ${ }^{4}$

It is an important public policy question whether the EU ETS is operating efficiently. One need only look at the titles and conclusions of some recent papers, to see that the dynamics of these markets may not be consistent with financial theory. For instance, the title of the paper by Daskalakis and Markellos (2008) "Are the European carbon markets efficient?" answers this question in the negative. Bredin and Muckley (2011) title their paper "An emerging equilibrium in the EU emissions trading scheme" and point to gradually maturing markets. However, Koop and Tole (2013) find considerable instability in forecasting models even very recently.

Investigating the linkages between the EU ETS and the CER markets is also of great importance. Allowing for CERs to count towards CO2 emissions quotas is crucial if $\mathrm{CO} 2$ emissions are to be reduced in a cost efficient fashion. For instance, if it is cheaper to reduce $\mathrm{CO} 2$ emissions via projects in China rather than fuel switching by EU electricity generators then it is economically

\footnotetext{
${ }^{2}$ One EUA gives the holder the right to emit one metric tonne of $\mathrm{CO} 2$.

${ }^{3} \mathrm{EU}$ member states have set individuals limits on the number of CERs that installations can use for compliance purposes. These range from $0 \%$ (Estonia) to $22 \%$ (Germany) of total emissions.

${ }^{4}$ Linacre, Kossoy and Ambrosi (2011), TheCityUK (2011) and Mizrach (2012) provide useful summaries of institutional details, problems, concerns and basic facts about the EU ETS and the CER markets.
} 
efficient to do so. Incorporating CERs into the EU ETS is currently the best mechanism for achieving such gains. If CERs were perfectly substitutable with EUAs, then the prices of these two assets would move together. However, as discussed below, there are several reasons why such perfect substitutability may not exist and arbitrage between the two markets may be limited. But, even if there is not perfect substitution between CERs and EUAs, there is likely to be some relationship and measuring its strength and nature is of interest to those in the finance industry investing in the carbon markets and to economists investigating whether $\mathrm{CO} 2$ emissions reductions are being achieved in an efficient manner.

Such considerations motivate the present paper. Using daily data since $2008,{ }^{5}$ we examine the nature of the relationship between the spot and futures markets in the EU ETS and investigate whether there are linkages with the CER carbon offset market. We also consider the question of whether these relationships are changing over time. To this end, we do not seek to impose financial theories specifying the relationship between futures and spot price on our data. Rather, we document the patterns in these carbon markets using reduced form multivariate time series models. In particular, we use time-varying parameter vector autoregressive (TVP-VAR) models that allow for multivariate stochastic volatility. This approach allows us to address questions such as: i) What are the causal relationships between these carbon markets?; ii) How does news affecting one price spill over onto the prices in other markets?; iii) Are there relationships between the EU ETS and the CER carbon markets?; and iv) Are there spillovers in volatility from one market to another?. Importantly, it allows us to answer all these questions in a time-varying manner in the context of a flexible model which lets the data speak.

Our main findings are that there is only weak evidence of Granger causality between any of the markets. What evidence there is indicates some timevariation where causality increased during the financial crisis. However, there is strong evidence of contemporaneous relationships between EU ETS spot and future prices and between EU ETS futures prices and CER futures. We present evidence that the EU ETS futures market is driving these relationships. We document time variation in these relationships and offer an explanation for why this might occur. We find little evidence for volatility spillovers except perhaps for the EU ETS spot and future markets.

The remainder of the paper is organized as follows: Section 2 reviews the related literature, emphasizing how the carbon markets differ from similar financial markets. Section 3 outlines our econometric methods and defines several important features of interest which are reported in our empirical results. Section 4 presents and discusses our empirical results. Section 5 concludes.

\footnotetext{
${ }^{5}$ The EU ETS is divided into phases with the second phase beginning in 2008 . This second phase will end in December 2012 which is the settlement date for the futures used in this paper.
} 


\section{Related Literature}

The carbon markets are relatively new and exhibit some unique characteristics. Nevertheless, they are related to commodity markets in general and energy markets in particular. Accordingly, we divide this section into two parts. In the first, we offer a very brief overview of some relevant literature relating to the commodity markets. In the second, we focus on the carbon markets.

\subsection{Commodity \& Financial Markets}

Modelling of the spot and future price relationship has often been framed in terms of the financial theory of commodities (see, e.g., Pindyck, 2001). The cost-of-carry relationship often plays an important role in these analyses. This theory argues that the future spot price will depend on the contemporaneous spot price and the cost of holding the commodity and a convenience yield. More formally, let $S_{t}$ be the spot price of a commodity at time $t, F_{t \mid T}$ be the futures price at time $t$ for delivery of the commodity at time $T, \delta$ be storage costs, $r$ be the risk free interest rate, and $c$ the convenience yield. Then the cost-of-carry relationship is:

$$
F_{t \mid T}=S_{t} \exp [(r+\delta-c)(T-t)] .
$$

There is also a large literature on the role of futures as reflecting expectations of future spot prices (e.g. Chinn and Coibion, 2010):

$$
F_{t \mid T}=E_{t}\left(S_{T}\right)+u_{t},
$$

where $E_{t}($.$) is the expected value given information available at time t$ and $u_{t}$ is an error term which, depending on context, can reflect several things (most importantly the risk premium). Note that, under the assumption that spot and future prices contain unit roots, either of these relationships can be used to justify a cointegrating relationship between spot and future prices (and, possibly, the interest rate).

A few examples of relevant papers investigating such relationships in energy markets include Longstaff and Wang (2004), Chevillon and Rifflart (2009) and Bolinger et al. (2006). Given that the present paper discusses time-variation in parameters, it is interesting to note that several papers in this literature document time-variation in parameters. For instance, Caporale et al. (2010) apply the cost of carry model using data from crude oil futures and spot markets. They use an econometric specification that allows for time variation in coefficients and find strong empirical support for this. Chin and Coibion (2010) also examine the relationship between spot and futures prices for a broad range of commodities, including some energy futures, with the aim of determining whether futures markets provide unbiased predictors for these markets' respective spot prices, as is implied by (2). This study also presents evidence of time variation in coefficients.

There is also a large literature on the search for an efficient price discovery mechanism. These studies revolve around the question of whether changes in 
the futures market tend to impact on the spot price market. Thus, the nature of the relationship and the speed of information transmission through to the spot market are key foci of interest. A completely efficient market implies that both spot and futures markets fully incorporate new information simultaneously. However, in reality, it is common to find that the futures market tends to lead the spot market in its ability to absorb information. This ability is due to it lower transaction costs, fewer institutional restrictions (e.g. on short selling) and greater liquidity (see, among many others, Tse, 1999). It is for these reasons that futures markets are often viewed as playing an important price discovery role for the underlying spot market. By way of example, Garbade and Silber (1983) develop and estimate a model of price discovery that incorporates the impact of arbitrage on price changes in selected spot and futures commodities markets. The model also allows for the determination of whether one market is dominant in terms of information flows and price discovery in seven different commodity markets. The authors find that futures markets tend to dominate cash markets, but that there are also reverse information flows from cash markets to futures markets. Figuerola-Ferrettia and Gonzalo (2010) improve on this model by considering the existence of convenience yields in spot-future price equilibrium relationships. Applied to spot and futures non-ferrous metals prices, they find that most markets are in backwardation, with futures prices leading in highly liquid futures markets. Bekiros and Diks (2008) investigate price discovery in the market for West Texas Intermediate oil (WTI) and find that, when taking into consideration non-linear effects to account for volatility, neither market leads or lags the other consistently; the pattern of leads and lags changes over time.

\subsection{Empirical Studies involving the Carbon Markets}

Compared to other commodity and financial markets, fewer empirical studies of carbon markets exist. Of these, most relate to the EU ETS, as opposed to the CER carbon offset market. Most of these empirical studies have focused on finding explanatory variables (e.g. relating to weather, energy prices or macroeconomic factors) that are useful for predicting carbon prices. Examples of this literature include Alberola et al. (2008a,b, 2009), Christiansen et al. (2005), Convery and Redmond (2007), Fezzi and Bunn (2009), Hintermann (2010) and Koop and Tole (2013).

However, a growing body of literature has empirically examined the relationship between spot and future prices. Papers in this literature cover different time periods ${ }^{6}$ and use different methodologies, so are sometimes difficult to compare. But it is fair to say that there is conflicting evidence over whether the underlying financial theories (such as those described in the preceding sub-section) hold for the EU ETS. Many papers also provide evidence of parameter change or other instabilities. Another common finding is that it is the futures market

\footnotetext{
${ }^{6}$ Phase 1 (which ran through the end of 2008) and Phase 2 (which ran through the end of 2012) of the EU ETS often exhibit different patterns.
} 
that plays the key role in price discovery. The following material surveys some of the literature which illustrates these points.

Milunovich and Joyeux (2010) use cointegration methods with spot and futures carbon prices and interest rates. They test for Granger causality and volatility spillovers. In addition, they allow for structural breaks, suggesting that coefficients are not constant over time. The authors find that none of the carbon futures are priced according to the cost-of-carry model. They do find some evidence of cointegration when working with futures with settlement dates in December 2006 and 2007 contracts, but not for the December 2008 settlement date. Granger causality and volatility spillover tests indicate the presence of information spillovers between the future and spot prices.

Truck, Hardle and Weron (2012) also conclude that a cost-of-carry relationship does not hold. Similarly, Chevallier et al. (2009) find no evidence that the cost-of-carry relationship holds for future contracts with maturation between 2008 and 2009. The authors conclude that the cost-of-carry model is not applicable to a market such as the EU ETS since there are no storage costs for carbon permits. In contrast, Uhrig-Homburg and Wagner (2009) do find evidence for the cost-of-carry relationship in their analysis, at least for much of the time. That is, they find arbitrage opportunities in the first year of the market in 2005, but find such opportunities disappeared afterwards. Results from their Vector Error Correction Model (VECM) indicate that the futures market leads discovery in the spot market.

In relation to the financial theory specified in (2), Chevallier (2010a) finds positive time-varying risk premia in the carbon market. However, the study was unable to discern whether futures prices were either upward- or downward biased predictors of expected spot prices. Chevallier et al. (2009) also document a high degree of instability in risk aversion and the risk premium. Note that the existence of a nonstationary risk premium would preclude the interpretation of (2) as specifying a cointegrating relationship between spot and future prices.

Chevallier (2010b) finds that, if a conventional VECM without structural breaks is used, cointegration between EU ETS spot and futures is found. However, tests indicate that a structural break is present. If an endogenous structural break is allowed for then the cointegration hypothesis is rejected. This author concludes "a vector autoregression appears more suitable to describe the data-generating process" (page 5). Also of relevance for our findings is the fact that the author concludes that the "vector autoregression model then shows that futures prices are relevant for price formation in the spot market, whereas the opposite is not true" (page 7).

Finally, another body of studies focusses on price discovery in the EU ETS. An important recent paper is Rittler (2012) which uses the information shares of Hasbrouck (1995) in order to investigate the relative roles of the spot and futures markets for EUA price discovery. We note that this measure assumes cointegration exists and is based on the coefficients on the error correction term in a vector error correction model. Thus, it requires cointegration to exist for it to be meaningful. Rittler (2012) does not find cointegration between spot and futures in the EU ETS at the daily frequency. As we shall see below, we 
also do not find cointegration with our daily data. However, Rittler (2012) also uses data at higher frequencies (i.e. 10 and 30 minute frequencies) and at these frequencies he does find cointegration. The information shares he calculates indicate that it is the futures market which plays the dominant role in the price discovery process. He also finds evidence of volatility spillovers, again from futures to spot markets (and not the reverse).

Daskalakis and Markellos (2008) measure the profitability of two trading rules compared to a naive investment strategies (e.g. random walk forecasts) to test for market efficiency. Empirical results indicate that the market is very inefficient, providing substantial opportunities to produce risk-adjusted profits. The authors attribute this inefficiency to a lack of liquidity in the market and the ban on short-selling and banking of EUAs.

The preceding discussion is of some of the literature which uses only EU ETS data. There are a few papers which combine EU ETS with CER data. Mizrach (2012) is perhaps the most thorough paper, investigating cointegrating relationships between a variety of spots and futures in various carbon markets trading on various exchanges. The extensive range of empirical work covered in this paper defies easy summary. But general patterns are that cointegration tends to be found for the same asset on different exchanges (e.g. spot EUAs on the Nord Pool and BlueNext exchanges are cointegrated with one another $)^{7}$ and between spot and near term futures. But other than these cases, evidence for cointegration is weak. For our purposes, his most important findings are that cointegration is not found between CERs and EUA spots or futures. This finding the author attributes to uncertainty about the bankability and eligibility of CER credits. Nazifi (2010) also investigates the links between CERs and EUAs and finds that cointegration is not present. Working with a VAR in first differences, Nazifi finds that movements in EUA prices Granger cause CER price movements but that the reverse does not occur. Chevallier (2010c), using data with a different time span than Nazifi, presents a similar finding where EUA prices influence CERs. In contrast, Chevallier (2010c) finds EUA and CER prices are cointegrated (although with a deterministic trend in the cointegrating relationship).

Mizrach and Otsubo (2013) is another recent paper using both EUA and CER data. Its focus, being on market microstructure issues, is different than ours. However, it is worth noting that the authors find that price discovery occurs in the futures market for EUAs. For CERs, a similar, but weaker result is found. Similarly, Medina et al. (2011) model intraday price discovery and information transmission between EUA and CER futures prices. They find that the EUA market leads in price discovery but that the CER market plays an important role far above its respective share in trading volume.

Most of the literature just discussed uses VAR or VECM models, ignoring volatility issues. But, with financial assets, time-varying volatility often occurs and can provide important information to the financial economist. Accordingly,

\footnotetext{
${ }^{7}$ Benz and Hengelbrock (2008) report similar findings for different exchanges using EUA data.
} 
it is worth noting that papers such as Chevallier (2011) and Rittler (2012) do explicitly model volatility and find EUA and CER prices to have time-varying volatilities. Paolella and Taschini (2008) and Gronwald and Ketterer (2012) consider extensions of GARCH models and provide strong empirical support for volatility changes and jumps. Similarly, Daskalakis, Psychoyios and Markellos (2009) present evidence in favor of continuous time jump diffusion models for EUA prices.

\subsection{Relation of Our Approach to the Literature}

This paper attempts to contribute to the existing empirical analyses of the relationship between spots and futures in the EU ETS and the CER carbon markets. As we have seen, the theoretical assumptions underlying the financial models necessary to motivate cointegration (e.g. that the variables have unit roots but that the unobserved risk premium is stationary) may not be valid. As discussed, the empirical evidence of whether these theories are applicable to the carbon markets is mixed. Thus we do not impose any financial theory or cointegrating relationship (e.g. as might be implied by equations 1 or 2). The inclusion of CER futures provides an additional reason for not imposing any particular financial theory. As mentioned, the latter market has become an increasingly important component of the EU ETS, allowing participants in the market to offset some of their emissions through the purchase of offset credits earned from carbon reduction projects in poor countries. CERs and EUAs have traded simultaneously since 2008. According to the European Commission's "linking directive", CERs and EUAs are completely fungible although member states can only use a prescribed number of CERs to cover domestic greenhouse gas emissions. The limit on average is about $13.5 \%$ (Trotignon, 2012). Being completely substitutable up to this limit, the two markets should be interrelated, but it is not clear how strong this relationship should be. Evidence (see, e.g., Mansanet-Bataller et al., 2010, and Medina et al., 2011) indicates a persistent spread between the two markets.

Finance provides theories linking spots and futures for the same asset or for the same asset being traded in different markets. But such conditions do not hold with CERs and EUAs. Due the the restrictions and uncertainties relating to the use of CERs in the EU-ETS discussed above, CERs are not perfectly substituable with EUAs. But nor are they completely different assets. There does exist some degree of substitutability between them that opens up the possibility of a relationship between the different carbon markets. The interesting research question is not so much whether this relationship is characterized by a specific financial theory, but what the strength of the relationship is and how it manifests itself. For such a purpose, it is useful to document the statistical relationships between the variables in our model viewed through a flexible time series model such as an unrestricted VAR with the error covariance modelled using some sort of multivariate stochastic volatility or GARCH process.

Moreover, in contrast to many studies, an important emphasis of our paper is the investigation of how patterns change over time. Coefficient change is 
rarely investigated in the existing literature, and usually only with the inclusion of dummy variables. However, if substantive coefficient change is present, then a model which ignores it will be mis-specified and the usual econometric problems associated with mis-specification will occur (e.g. estimates will be biased) and important patterns may be missed. This motivates our use of a TVP-VAR which means that we can explicitly model coefficient change (and change in the error variances and covariances in our model). This approach allows us to uncover patterns in a flexible and time-varying fashion, without imposing a particular financial theory on the data. As we shall argue below, if financial theories such as the cost-of-carry approach are true and we ignore this, the only cost will be that our estimates are less precise (i.e. in the sense that failing to impose a true restriction will tend to lead to less precise estimation of the remaining parameters in a model). Our empirical results suggest that some parameters are time-varying and the relationship between the variables is not simply the one implied by, e.g., the cost-of-carry relationship.

Our main results are for multivariate time series models where we investigate the relationships between the spot and futures price of a European carbon permit, the futures price of a carbon offset and the interest rate. The inclusion of the interest rate is motivated by the cost-of-carry relationship. However, in an online appendix we also present results for smaller sets of variables. In particular, the online appendix presents results that omit the carbon offset variables (so as to focus solely on the three variables involved in the cost of carry relationship for the EU ETS) in addition to results omitting the spot price of the EU ETS carbon permit and interest rate (so as to focus solely on the relationship between the EU carbon permit and offset markets using the most comparable variable in each). Empirical insights from these smaller multivariate time series models are similar to those from the larger multivariate time series model.

In summary, our econometric methodology is motivated by the following considerations: 1) We want to model spot and futures prices in the EU ETS along with the interest rate and the carbon offsets price jointly. 2) We want coefficients in the model to change over time. 3) We want volatility to change over time. At the broadest level, this approach will allow us to model the dynamics of the relationship between spot and futures markets. More specifically, it will allow us to investigate spillovers and Granger causality and pass-through (e.g. do changes in the spot price cause the futures price to change? If yes, then by how much and when?). It will allow us to investigate whether these features are changing over time. Finally, it will also allow us to investigate patterns in the volatility (i.e. addressing questions such as: is the volatility of the spot and futures markets changing over time? Are there spillovers here as well? For example, if the spot market is volatile at a point in time will this feed through and also cause the futures market to be volatility?, etc.). 


\section{Econometric Methods}

\subsection{The TVP-VAR}

The TVP-VAR is a model, increasingly popular in macroeconomics and finance, which has all of the characteristics listed at the end of the previous section (see, among many others, Cogley and Sargent, 2001, 2005, Cogley et al., 2005, Primiceri 2005, Baumeister, Durinck and Peersman, Clark and Davig, 2008, Koop et al., 2009, Mumtaz and Surico 2009 and D'Agostino et al., 2013 ). In this paper, we use the specification of Primiceri (2005) estimated as described in Del Negro and Primiceri (2013).

Let $y_{t}=\left(s_{t}, f_{t}, i_{t}, c e r_{t}\right)^{\prime}$ where $s_{t}$ is the log of the spot price of a carbon permit, $f_{t}$ is the log of the futures price of a carbon permit, $i_{t}$ is the log of the interest rate and $c r_{t}$ is the $\log$ of the price of a carbon offset, for $t=1, . ., T$. We also repeat the econometric analysis with differenced data and, in this case, $y_{t}=\left(\Delta s_{t}, \Delta f_{t}, \Delta i_{t}, \Delta c e r_{t}\right)^{\prime}$.

The TVP-VAR can be written as

$$
y_{t}=Z_{t} \theta_{t}+\varepsilon_{t}
$$

where $Z_{t}$ is an $n \times m$ matrix structured as:

$$
Z_{t}=\left(\begin{array}{cccc}
z_{t}^{\prime} & 0 & \cdots & 0 \\
0 & z_{t}^{\prime} & \ddots & \vdots \\
\vdots & \ddots & \ddots & 0 \\
0 & \cdots & 0 & z_{t}^{\prime}
\end{array}\right)
$$

where $z_{t}$ is a vector containing an intercept and $p$ lags of all of the dependent variables. The number of variables is $n$ (in our benchmark model $n=4$ ) and $m=n(1+p n)$. The errors, $\varepsilon_{t}$, are assumed to be independent $N\left(0, H_{t}\right)$. The VAR coefficients are allowed to evolve over time as:

$$
\theta_{t}=\theta_{t-1}+\eta_{t}
$$

and $\eta_{t}$ are independent $N(0, Q)$.

Note that this takes the form of a state space model and the time-varying VAR coefficients can be interpreted as an $m \times 1$ vector of unobserved states. This specification has the advantage that standard statistical methods for state space models exist and TVP-VARs have been found to be able to capture a variety of types of change in coefficients. ${ }^{8}$ That is, they are best able to model gradual change in coefficients, but have been also found to approximate well more abrupt structural breaks or other types of coefficient change.

In order to allow for time varying volatility and possible volatility spillovers, the error covariance matrix in (3) is assumed to follow a multivariate stochastic

\footnotetext{
${ }^{8}$ See Koop and Korobilis (2009) which surveys this literature and links with computer code for estimating TVP-VARs and related models.
} 
volatility process. To be precise, we use a triangular decomposition and write the $n \times n$ matrix $H_{t}$ as

$$
H_{t}=A_{t}^{-1} \Sigma_{t} \Sigma_{t}^{\prime}\left(A_{t}^{-1}\right)^{\prime}
$$

where $\Sigma_{t}$ is a diagonal matrix with diagonal elements $\sigma_{j, t}$ for $j=1, . ., n$ and $A_{t}$ is a lower triangular matrix with ones on the diagonal. E.g. in the case where $n=4$ :

$$
A_{t}=\left(\begin{array}{cccc}
1 & 0 & 0 & 0 \\
a_{21, t} & 1 & 0 & 0 \\
a_{31, t} & a_{32, t} & 1 & 0 \\
a_{41, t} & a_{42, t} & a_{43, t} & 1
\end{array}\right) .
$$

Note that this decomposition writes the error covariance matrix in terms of $\sigma_{j, t}$, which is the standard deviation of the error in equation $j$ and $A_{t}$ which determines the correlations between the errors in the different equations (e.g. if $a_{21, t}=0$ then the correlation between the errors in the first and second equations is zero).

Let $\sigma_{t}=\left(\sigma_{1, t}, \sigma_{2, t}, \ldots, \sigma_{n, t}\right)^{\prime}$ and $a_{t}=\left(a_{21, t}, a_{31, t}, \ldots, a_{n(n-1), t}\right)^{\prime}$. These are allowed to evolve according to the state equations:

$$
\log \left(\sigma_{t}\right)=\log \left(\sigma_{t-1}\right)+u_{t}
$$

and

$$
a_{t}=a_{t-1}+v_{t}
$$

where $u_{t} \sim i . i . d . N(0, W), v_{t} \sim i . i . d . N(0, C)$, and $u_{t}$ and $v_{t}$ are independent to each other with all the leads and lags. As discussed in Primiceri (2005), this specification is a flexible one, allowing both error variances and covariances to evolve over time. ${ }^{9}$

\subsection{Levels or Differences?}

Some of the related literature investigates the unit root or cointegration properties of variables similar to the ones used in this paper. However, for both empirical (e.g. the largely negative empirical support for cointegration when using daily data noted above) and theoretical reasons this is not a focus of the present paper. In the Bayesian VAR literature it is common to work with macroeconomic variables in levels, without worrying about unit root or cointegration issues. For instance, Sims (1988) demonstrates the unimportance of such issues for Bayesian inference in multivariate time series models with constant coefficients. At worst, by failing to impose a true cointegrating relationship, some accuracy of estimation is lost. But if cointegration is not present or cointegrating relationships hold only at some points in times (as empirical evidence indicates with this data set), mis-specification will result by imposing cointegration.

With the TVP-VAR, unit root and cointegration issues are even less important since (4) puts an intercept in each equation which could evolve according

\footnotetext{
${ }^{9} \mathrm{C}$ has a block diagonal structure as specified on Primiceri (2005, page 825) or in the Prior Appendix.
} 
to a random walk. This can account for any unit root non-stationarities in each dependent variable not otherwise explained by the lagged dependent variables which appear in each equation of the TVP-VAR. In our data set, both the Johansen and Engle-Granger tests (with one lag, regardless of whether constants are included or not) indicate that a cointegrating relationship is not present between the EUA spot, future and CER carbon offset (nor in the bivariate relationship between the EUA spot and futures).

In light of these considerations, the main results in our paper use the loglevels of all variables as dependent variables and we do not impose any cointegrating restrictions on our models. However, as a robustness check, we repeat the entire analysis using log differences of all the variables. Results for this latter case are put in the online appendix associated with this paper and are briefly discussed below.

\subsection{Features of Interest from the TVP-VAR}

TVP-VARs with multivariate stochastic volatility can be used to measure the intertemporal relationships (in both the conditional mean and conditional variance) between variables in a time-varying fashion (see, e.g., Clark and Davig, 2008). We present evidence relating to Granger causality, the correlations between the errors in the different equations and the way the volatilities evolve.

With daily financial data, there is rarely a need to work with more than one lag of the dependent variable (and our empirical findings indicate one lag is adequate). In this case, the coefficient on the lag of each individual variable is relevant for Granger causality. In particular, the coefficient on the lag of variable $\mathrm{i}$ in the equation for variable $\mathrm{j}$ sheds light on whether past values of variable $\mathrm{i}$ have predictive power for variable $\mathrm{j}$ (after controlling for lags of other variables). There are sixteen of these coefficients (i.e. in each of four equations we check for Granger causality for each of the four variables). Importantly, the TVP-VAR allows us to do this is a time-varying fashion so as to see if Granger causality relationships are changing over time. Furthermore, we calculate the probability that each Granger causality restriction holds at each point in time. ${ }^{10}$ Results for longer lag lengths (available in the online appendix) are based on the sum of coefficients on lags of variable $i$ in equation $j$.

With relation to the error covariance matrix, in addition to presenting estimates of the volatilities themselves $\left(\sigma_{j, t}\right)$, we provide estimates of the timevarying correlations between the errors. We also calculate the probabilities that these correlations are zero in a time-varying fashion. These correlations, based on $H_{t}$, tell us whether unexpected shocks to one variable are related to another. Suppose for instance, there was some unexpected shock that impacted on the entire European carbon market and had a long lasting effect (e.g. a recession caused a reduction in economic activity and, hence, CO2 emissions). One would

\footnotetext{
${ }^{10}$ Note that this is different from calculating the probability (or doing a standard hypothesis test) that Granger causality holds. Such standard procedures will shed light on whether Granger causality holds at all times but does not allow for it holding at some points in time but not others.
} 
expect this to have an impact on both spot and futures prices. If shocks are of this nature then we would expect there to be a strong correlation between the errors in the spot and futures equations. However, a short temporary shock (e.g. an unusually cold winter in one year) may impact only on the spot market but have little effect on carbon futures with a distant settlement date. If shocks are of this nature, then we would not expect strong correlation between errors in spot and futures equations.

The preceding discussion involves questions relating to how lags of one variable or unexpected shocks impact on another variable. These are distinct from questions relating to relationships between the volatilities of the variables. Papers such as Rittler (2012) have investigated volatility spillovers in the carbon market using multivariate GARCH specifications. With our multivariate stochastic volatility specification given in (5), (6) and (7), it is $W$ (the covariance matrix of errors in the volatility equations) that can be interpreted as controlling such spillovers. That is, (6) specifies the evolution of the volatilities (i.e. the logs of the standard deviations of the errors) in each equation. If $W$ is a diagonal matrix then these volatilities are evolving independently of one another and there are no spillovers. But if off-diagonal elements are non-zero then the movement of the volatilities will be correlated. A shock to one of the volatilities (i.e. one element of $u_{t}$ ) will then have an impact on other volatilities. In our empirical work, we present the correlation matrix of $u_{t}$ (which can be derived from $W$ ) to shed light on such volatility spillovers.

\subsection{Estimation of the Features of Interest}

Econometric inference in the TVP-VAR is typically done using Bayesian methods. Details of the posterior simulation algorithm, which uses standard Markov chain Monte Carlo (MCMC) algorithms for state space models, are available in many places (e.g. Primiceri, 2005, Cogley and Sargent, 2005 and Koop and Korobilis, 2009). The precise algorithm we use is described in Del Negro and Primiceri (2013). MCMC diagnostics for our benchmark model are provided in the online appendix.

Bayesian methods require the use of a prior for the initial conditions for the states $\left(\theta_{0}, \log \left(\sigma_{0}\right), a_{0}\right)$ and the error covariance matrices in the state equations $(Q, W, C)$. We use the training sample prior approach of Primiceri (2005) and Cogley and Sargent (2005) in order to calibrate the prior. This approach uses OLS estimates from a VAR using an initial set of observations (in our case 10 days) to choose the prior hyperparameters. The TVP-VAR is then estimated using this prior and the remainder of the data. Precise details are given in the appendix.

The estimation and prior elicitation methods described so far are commonlyused in the empirical literature using TVP-VARs and, hence, a detailed explanation is not given. However, calculating time-varying probabilities of features of interest is less familiar. Hence a more detailed explanation is required. We use an approach developed in Koop et al. (2010) and explain the basic idea here. Let $\omega_{t}$ be a time-varying feature of interest (e.g. an element of $\theta_{t}$ or $a_{t}$ ). To 
calculate the probability that $\omega_{t}=0$ we proceed as follows. Consider two models: the unrestricted TVP-VAR above $\left(M_{1}\right)$ and the restricted TVP-VAR which imposes the restriction that $\omega_{t}=0\left(M_{2}\right)$. The posterior odds ratio comparing the restricted to the unrestricted model is:

$$
P O=\frac{\operatorname{Pr}\left(M_{2} \mid y\right)}{\operatorname{Pr}\left(M_{1} \mid y\right)} .
$$

The posterior odds ratio can be used to calculate the probability of the unrestricted model: $\operatorname{Pr}\left(M_{1} \mid y\right)=\frac{1}{1+P O}$. We calculate this for every time period. $\operatorname{Pr}\left(M_{1} \mid y\right)$ is what we present in our empirical results. $\operatorname{Pr}\left(M_{2} \mid y\right)$ is one minus this.

In order to calculate this posterior odds ratio, we use the Savage-Dickey density ratio (see, e.g., Verdinelli and Wasserman, 1995). This uses the result that (assuming each model is, a priori, equally likely and same prior holds in each model) the posterior odds ratio can be written as:

$$
P O=\frac{p\left(\omega_{t}=0 \mid y\right)}{p\left(\omega_{t}=0\right)}
$$

where $p\left(\omega_{t}=0 \mid y\right)$ and $p\left(\omega_{t}=0\right)$ are, respectively, the prior and posterior for the unrestricted TVP-VAR evaluated at the point $\omega_{t}=0$. Note that the numerator and denominator are both easy to calculate. For restrictions involving $\theta_{t}$ and $a_{t}$, the denominator is given by the hierarchical prior defined in the state equations (4) and (7). The numerator can be obtained from MCMC output from the unrestricted TVP-VAR (note that the conditional posteriors used in the MCMC algorithm for both $\theta_{t}$ and $a_{t}$ are Normal which makes calculation of the numerator simple). See Koop et al. (2010) for complete details and formulae.

\subsection{Additional Motivation for the TVP-VAR}

TVP-VARs have the advantage that they are flexible models, allowing the data to speak and decide whether specific parametric restrictions hold or not and whether coefficient variation occurs or not. In a case such as ours, where much of the previous evidence indicates that theoretical restrictions (e.g. cointegration) do not hold and the relevant financial markets are possibly immature or unstable, we would argue that working with a TVP-VAR is a good way of investigating the relationships between our variables. If a simpler VAR or VECM adequately characterizes the data, then the TVP-VAR will approximate it. But in the presence of parameter change, the VAR or VECM will be mis-specified whereas the TVP-VAR will not be. BICs select the TVP-VAR over the constant coefficient VAR. However, most of the variation is found in the error covariance matrix. To elaborate on this point, remember that $Q, W$ and $C$ controls the degree of parameter change in the VAR coefficients, the error variance and the error covariances, respectively. By setting any of these parameters to zero we obtain a restricted model where coefficient change does not occur. We have 
estimated restricted TVP-VARs which impose such restrictions. BICs indicate the following ranking of models: i) TVP-VAR with $Q=0$, ii) unrestricted TVP-VAR, iii) TVP-VAR with $C=0$ and iv) TVP-VAR with $W=0$. Thus, a constant coefficient VAR with multivariate stochastic volatility of an unrestricted form is preferred by the data. Our unrestricted TVP-VAR allows us to uncover this in the context of estimating a single model. The empirical results in the next section are for the unrestricted TVP-VAR but are very similar to the restricted TVP-VAR which imposes $Q=0$.

\section{Empirical Results}

\subsection{The Data}

In our empirical results, we use the terminology spot, future and offset, where spot/future refer to the spot/future price of the EU ETS carbon permit and offset refers to the price of a CER carbon offset. Daily data on futures prices for both EUAs and CERs were obtained from the ECX (European Climate Exchange). Sufficient data were unavailable for CER spot prices, which is why we only use the futures price for the carbon offset. For both future price variables, we use a December 2012 contract settlement date. Daily spot prices for EUAs were obtained from the Bluenext Exchange. We also include an interest rate variable - the Euribor rate. This series was obtained from Thompson Datastream and is a short-term (monthly) interest rate. Figure 1 plots these variables. A cursory look indicates that there is a rough concordance between the spot, future and carbon offset variables. And for the EU ETS spot and future markets a contango relationship is noticeable. 


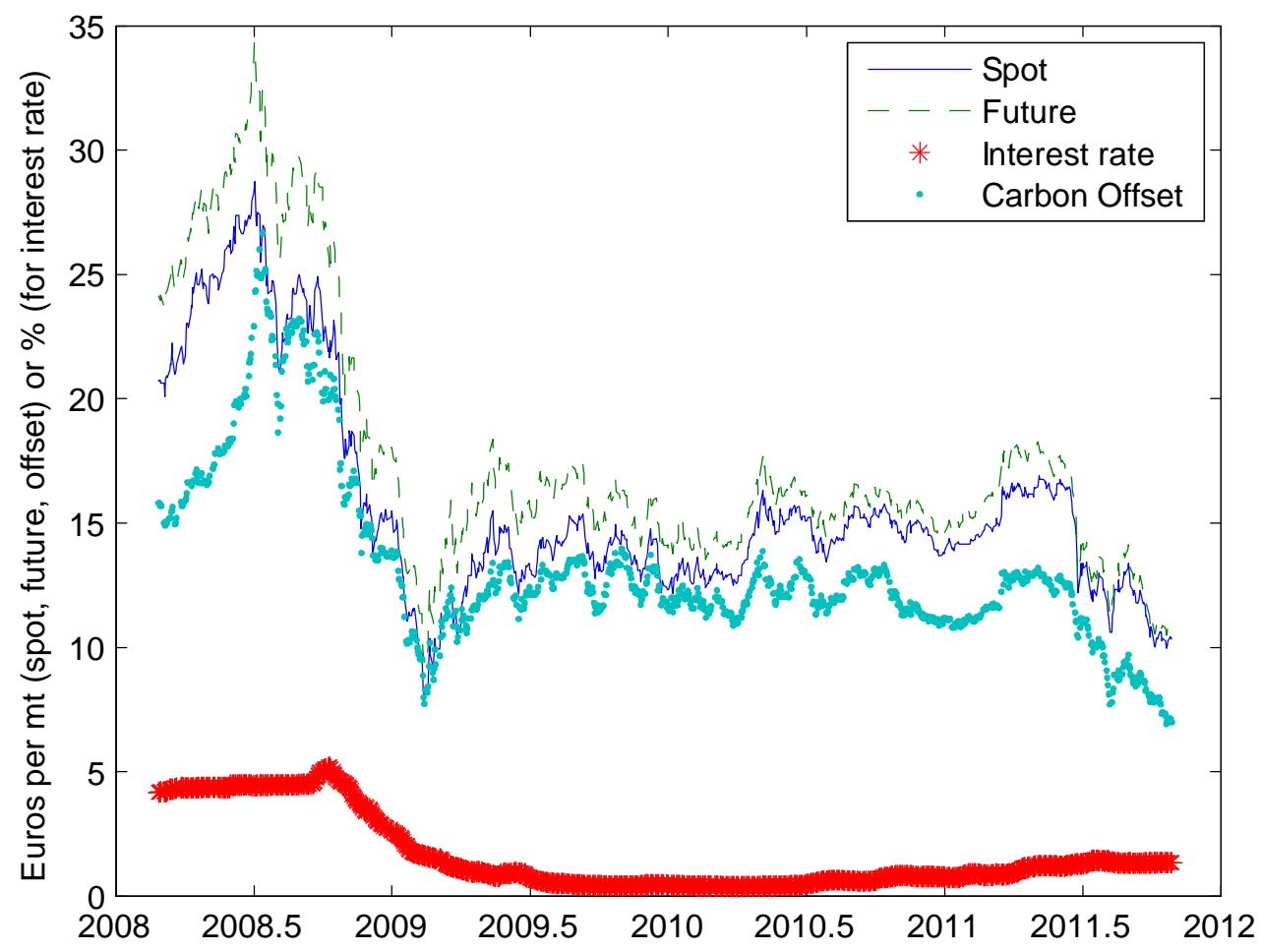

Figure 1: Plot of the Data

\subsection{Time-Varying Probabilities of Features of Interest}

The results presented in this sub-section are for the case where: i) all four variables are used in the TVP-VAR; ii) the dependent variables are in levels; iii) one lag is used in the TVP-VAR; and iv) the training sample prior is used (see the Prior Appendix for explanation and justification). A subsequent sub-section discusses robustness to all four of these aspects (with complete empirical results for these other cases put in an online appendix). Since most of our features of interest are time-varying, we present most our results in terms of figures.

If all four of our variables simply followed random walks, independent of one another then we would expect: i) the coefficient on the first own lag in each equation (i.e. the lag of variable $i$ in the equation with variable $i$ as dependent variable) to be one at all points in time; ii) all the coefficients on other lags (i.e. lags of variable $\mathrm{j}$ in equation $\mathrm{i}$ ) to be zero; and iii) the correlations between the errors in the four equations to all be zero. Thus, we would expect to find Granger 
causality for own variables (e.g. variable i should Granger cause itself) but not any of the other variables. We interpret our results below with this extreme case in mind. With respect to the VAR coefficients, we are not too far from this independent random walks case. As we shall see, the inter-relationships between the variables manifest themselves through the error correlations.

Figures 2 through 4 plot the probabilities of each variable Granger causing the spot, futures and carbon offset variables, respectively. For the sake of brevity, we do not plot the comparable figure for the interest rate equation. Given the focus of this paper, questions relating to the interest rate are of less interest. The results for the interest rate indicate that none of the other variables Granger cause it and it evolves according to an AR process with coefficient near unity.

With the exception of the spot price, the probabilities that the first own lags in each equation are non-zero are nearly one in all time periods. For the spot price, its first own lag is very important up to the first half of 2009, but subsequently decreases. In practice, this is due to the first own lag coefficient decreasing over time with some of the spot dynamics being captured by other variables (although these latter effects are not that strong). ${ }^{11}$

None of the coefficients on the other lags has a probability being near one. Some of them have probabilities of 0.20 or more and there is some time-variation in a few of these probabilities. But none of these results relating to other lags is strong. In general we must conclude that we are finding very little evidence of Granger causality from any variable to any other variable. One might have expected, for instance, that a change in the futures price one day would impact on the carbon offset price the next day. We are finding very little evidence of effects such as this. What little evidence for Granger causality that does occur happens in early 2009 around the time of the financial crisis. The implications of the financial crisis for the carbon markets will be discussed below.

For brevity, we do not provide graphs of the time-varying VAR coefficients themselves. With the exceptions noted above, they are consistent with random walk behavior for each variable. The interested reader is referred to the online appendix which includes complete empirical results.

\footnotetext{
${ }^{11}$ If we simply estimate a univariate TVP-AR model for the spot price, we observe a similar decline in the AR coefficient over time, although one that is less extreme than what is found with the TVP-VAR.
} 


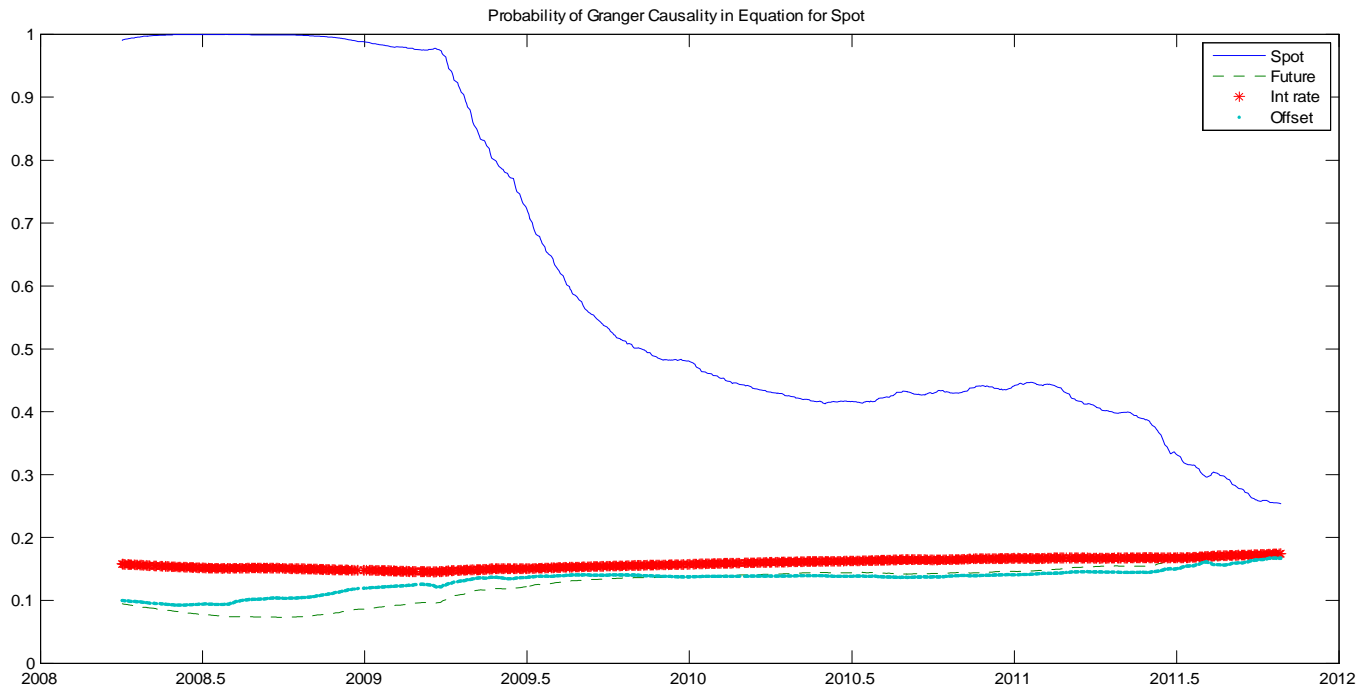

Figure 2

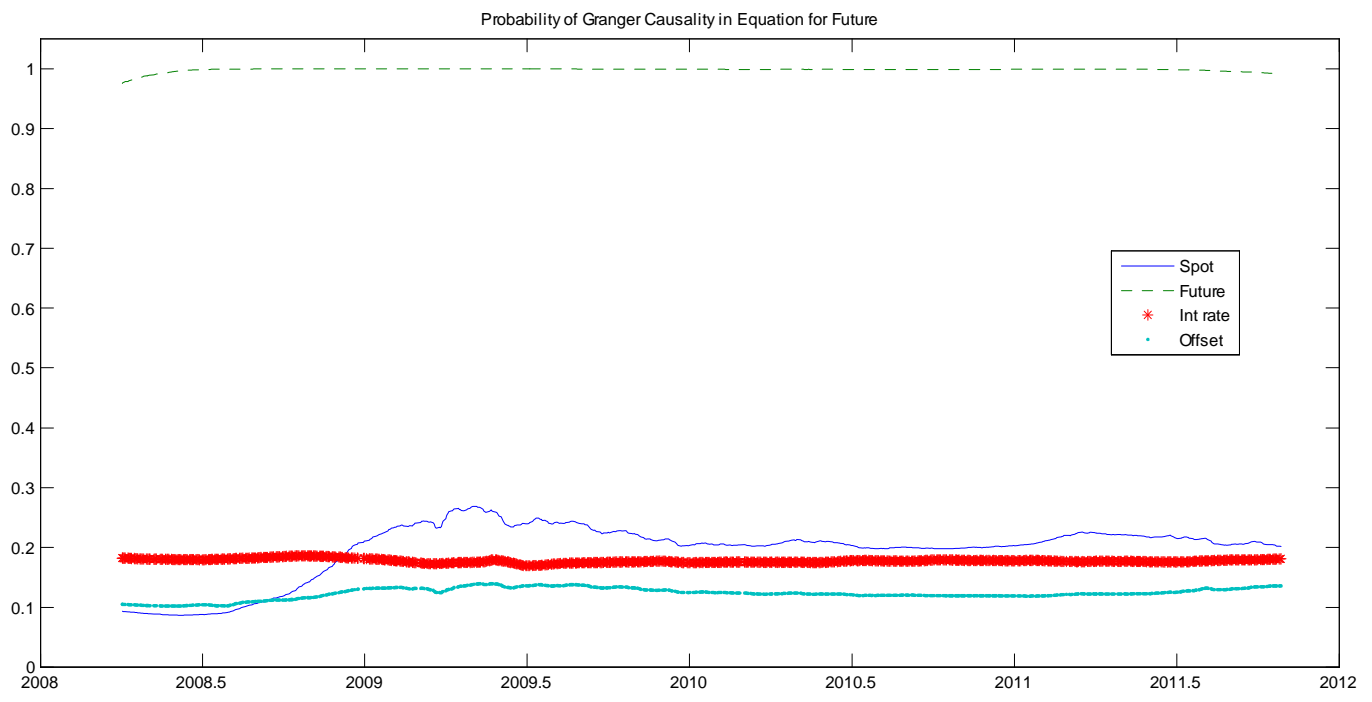

Figure 3 


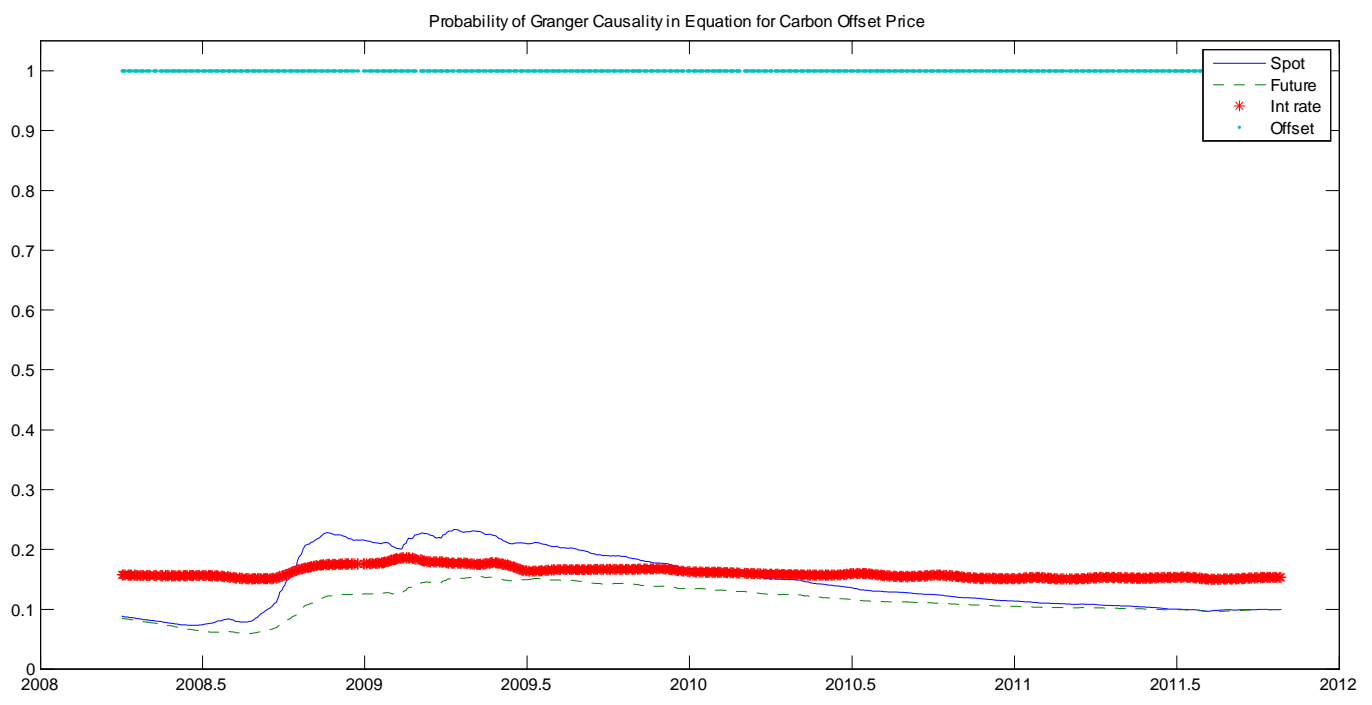

Figure 4

Our Granger causality results show little evidence of lagged effects where changes in one variable impact on another the following day. Instead we are finding evidence of more immediate relationships via the error covariance matrix $H_{t}$. These relationships can be seen in Figures 5 through 7, which plot the timevarying probabilities of the correlations between the errors in different equations being non-zero. Several of these correlations do seem to be zero. However, there are two cases where strong correlations exist. The correlation between the errors in the spot and future equations is always extremely strong. And the correlation between the errors in the offset and future equations is strong for much of the time. Figures 8 and 9 plot point estimates of these two correlations (along with +/- 1 standard deviation bands). For the sake of brevity, graphs for the other correlations are placed in the online appendix.

With regards to the non-zero correlations plotted in Figure 8 and 9, these indicate a strong, positive, contemporaneous relationship between the spot, future and offset markets. It is perhaps unsurprising that these three closely related markets should be inter-related and that, in fast-moving financial markets, this inter-relationship should reveal itself to be contemporaneous. However, the way that this relationship manifests itself is interesting. It seems that the EU ETS future price is playing the central role in the sense every other variable is correlated with it, but these other variables are not correlated with each other. To be precise, the errors in the futures equation are correlated with the errors in the spot and offset price equations (and, as noted above, there is weak evidence of a correlation between futures and interest rate equation errors). However, 
the errors in none of the other equations are correlated with each other. In particular the errors in the spot and carbon offset equations are uncorrelated with one another. This dominance of the futures market is explained by the fact that futures account for the bulk of trading in the European carbon markets. It is consistent with the literature (e.g. Benz and Hengelbrock, 2008, and Benz and Truck, 2009) surveyed in Section 2 that argues that futures markets play a more important role in price discovery than the underlying spot market.

The correlation between EU ETS spot and futures markets is strong at all points in time. But there is a noticeable increase in the correlation between the two variables in late 2008 and early 2009 at the height of the financial crisis. The demand for carbon permits was severely affected in late 2008 and early 2009 as the economic crisis hit output. The anticipated decline in industrial $\mathrm{CO} 2$ emissions led to a sell-off in the carbon markets. The price decline can be seen in Figure 1. The shock of the financial crisis affected the EU ETS carbon markets as a whole and, hence, spot and futures markets became especially highly correlated at this time. After mid 2009 the futures and spot prices were roughly stable until mid 2011 and the correlation between spot and futures markets declined slightly (presumably idiosyncratic shocks played more of a role). The European debt crisis of the latter half of 2011 was associated with another fall in carbon prices and a slight increase in this correlation.

In sum, we are finding that the EUA spot and futures markets are strongly contemporaneously correlated with one another. We are also finding some evidence that this correlation strengthens at times of price falls associated with important events affecting the economy as a whole.

The correlation between the EUA and CER futures prices also exhibits a large increase at the time of the financial crisis. However, this correlation does not decrease subsequently and remains high throughout the latter half of 2009 and through 2010. It then declines slightly in 2011. These patterns are likely accounted for by some unique characteristics of the CER markets. The role of carbon offsets was expected to increase with time as firms were allowed to use more of these offsets to cover their CO2 emissions. It is likely that this factor and the common shock of the financial crisis accounts for the increasing correlation between EU ETS and CER prices throughout the first part of our sample. Indeed Figure 1 shows how the price gap between EU ETS futures and CER carbon offsets narrowed substantially at the beginning of our sample. However, as time went on, the source of CERs, the Clean Development Mechanism (CDM), faced worsening problems with regulation and issuance (Linacre et al., 2011). Supply problems were also compounded by growing uncertainty over how CER allowances would be counted in the future. Throughout 2011 the future of the Kyoto protocol became increasingly in doubt. By the end of 2011, the much waited UN conference in Durban failed to deliver a post-Kyoto treaty, intensifying uncertainty about whether CDM projects would even be registered with the UN beyond 2012. This uncertainty was exacerbated by the failure of other carbon trading initiatives elsewhere in the world (e.g. in the USA).

The consequence was that the EU ETS was left to absorb an oversupply of CERs. It is likely that these latter factors account for the decrease in the 
correlation in 2011 seen in Figure 9.

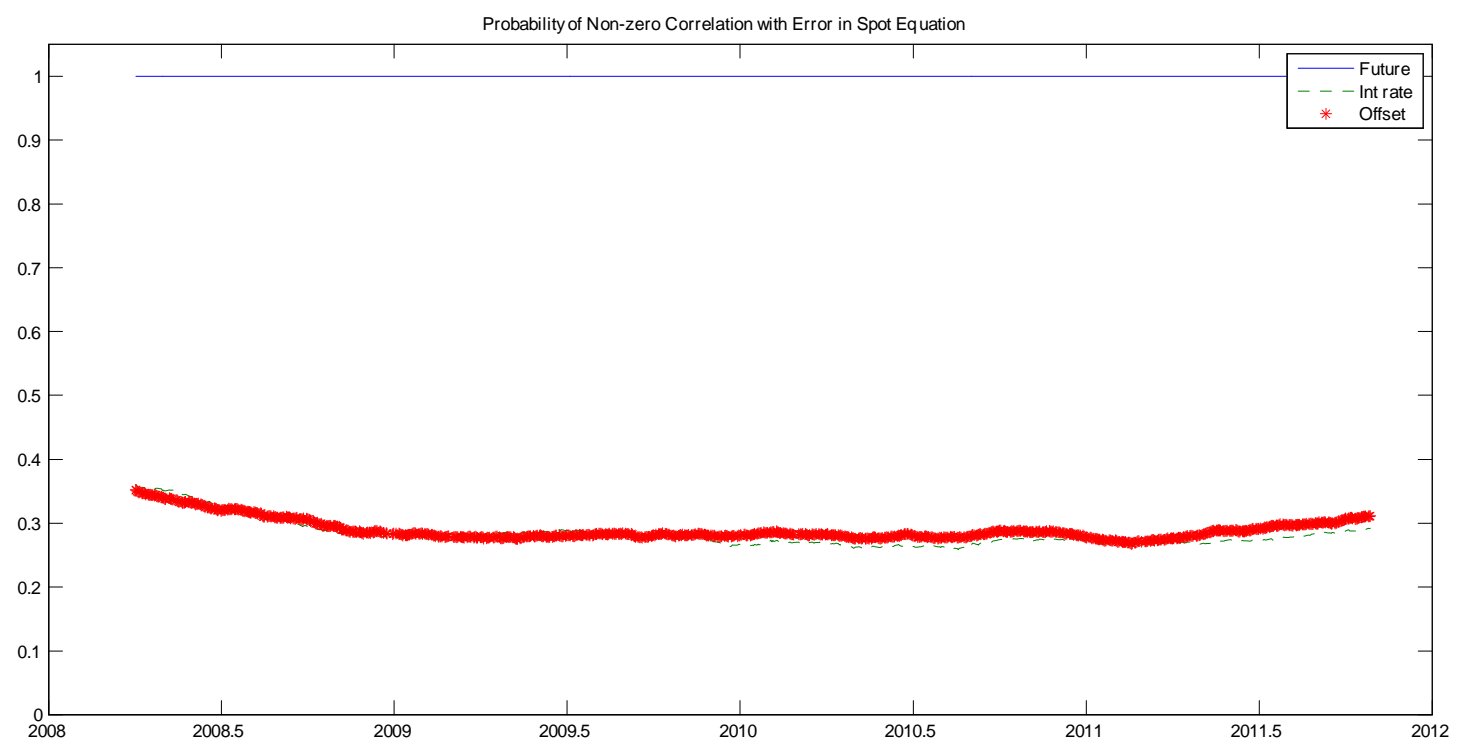

Figure 5 


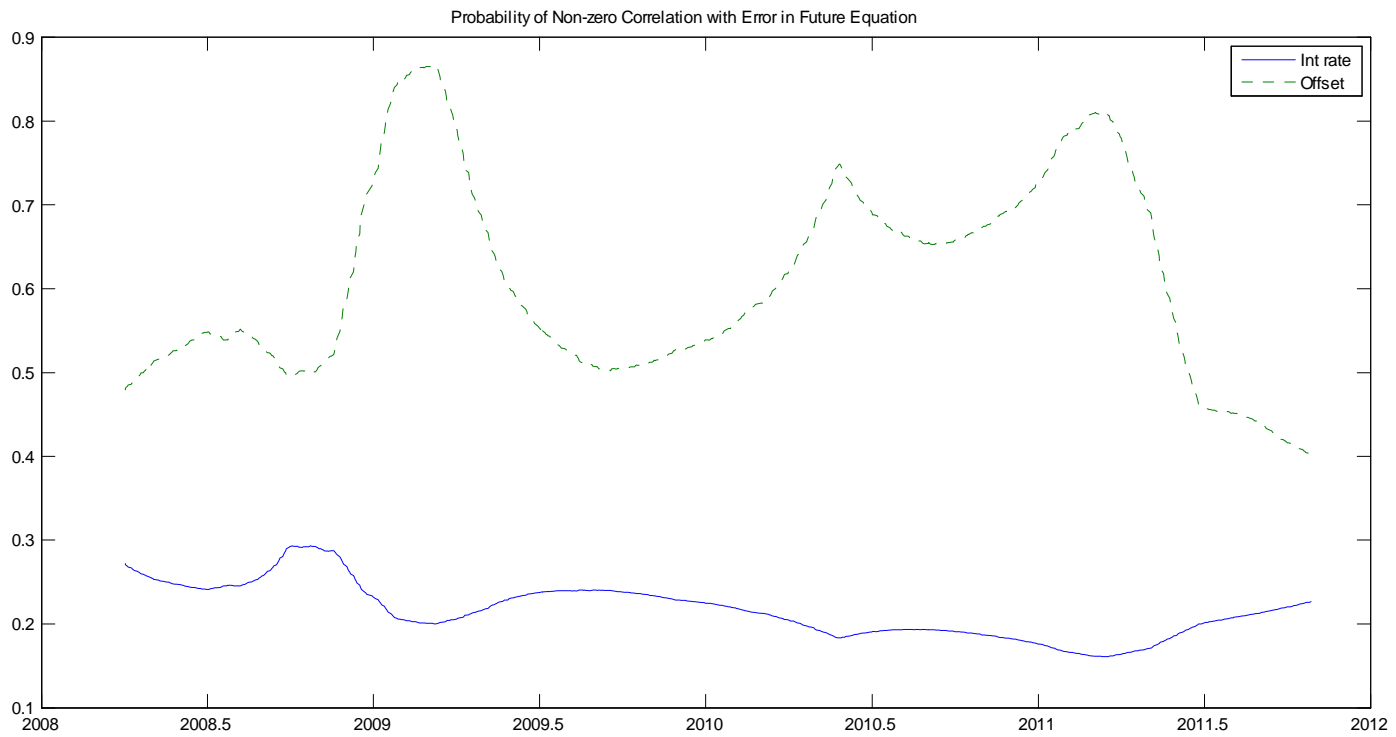

Figure 6

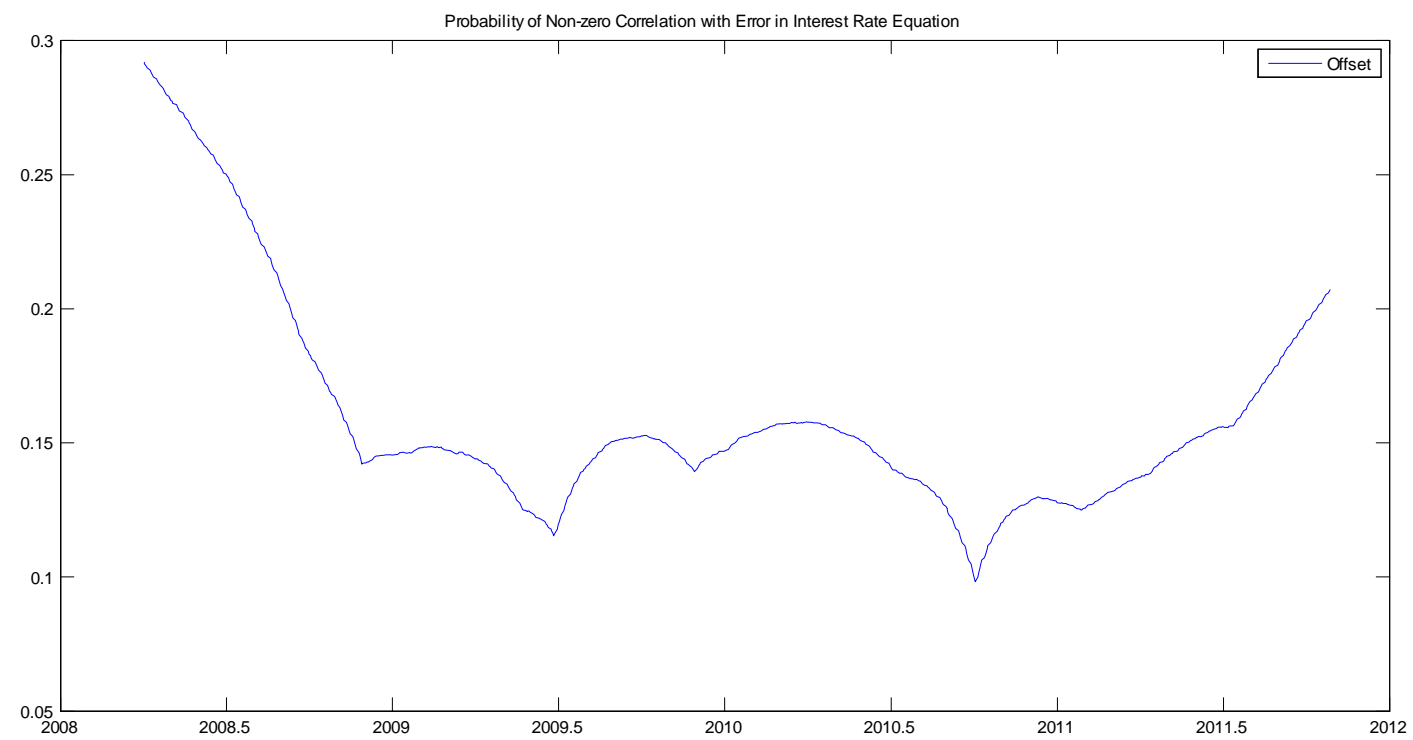

Figure 7 


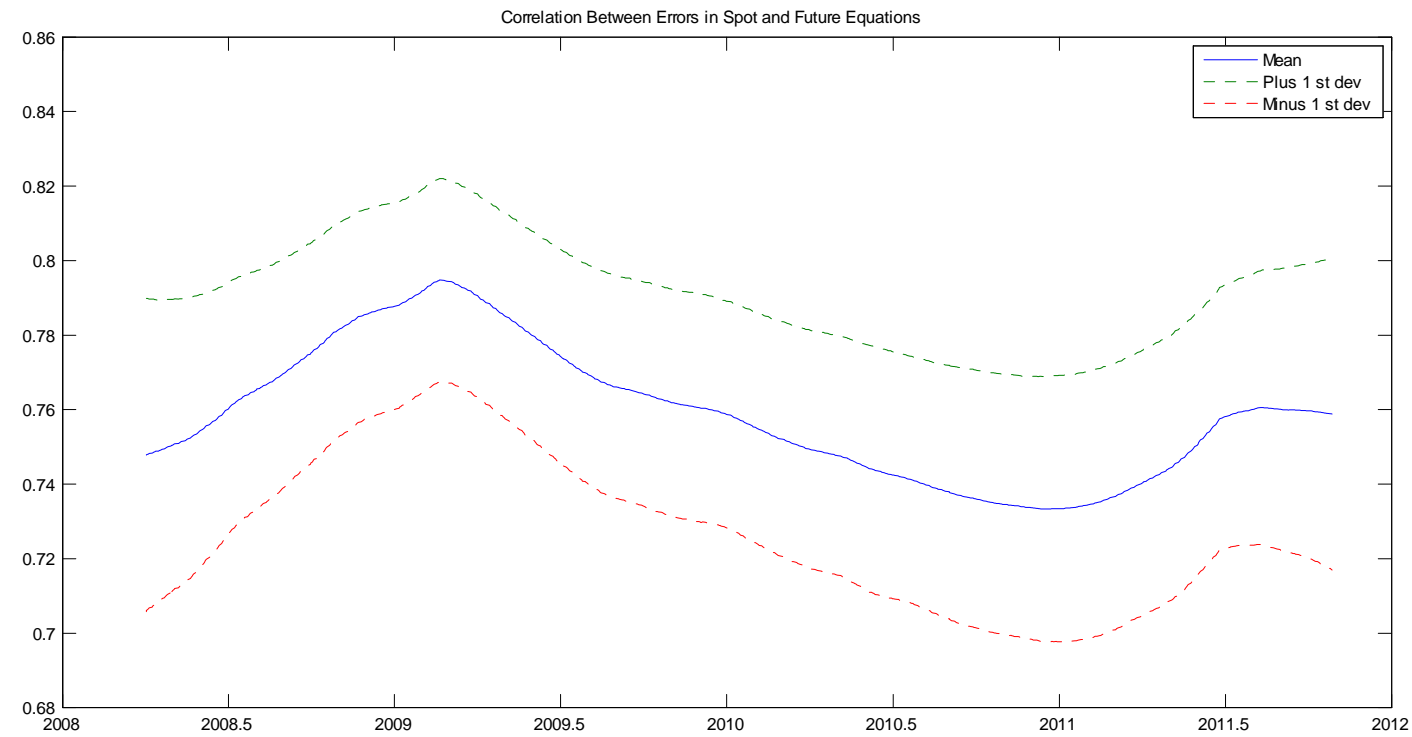

Figure 8

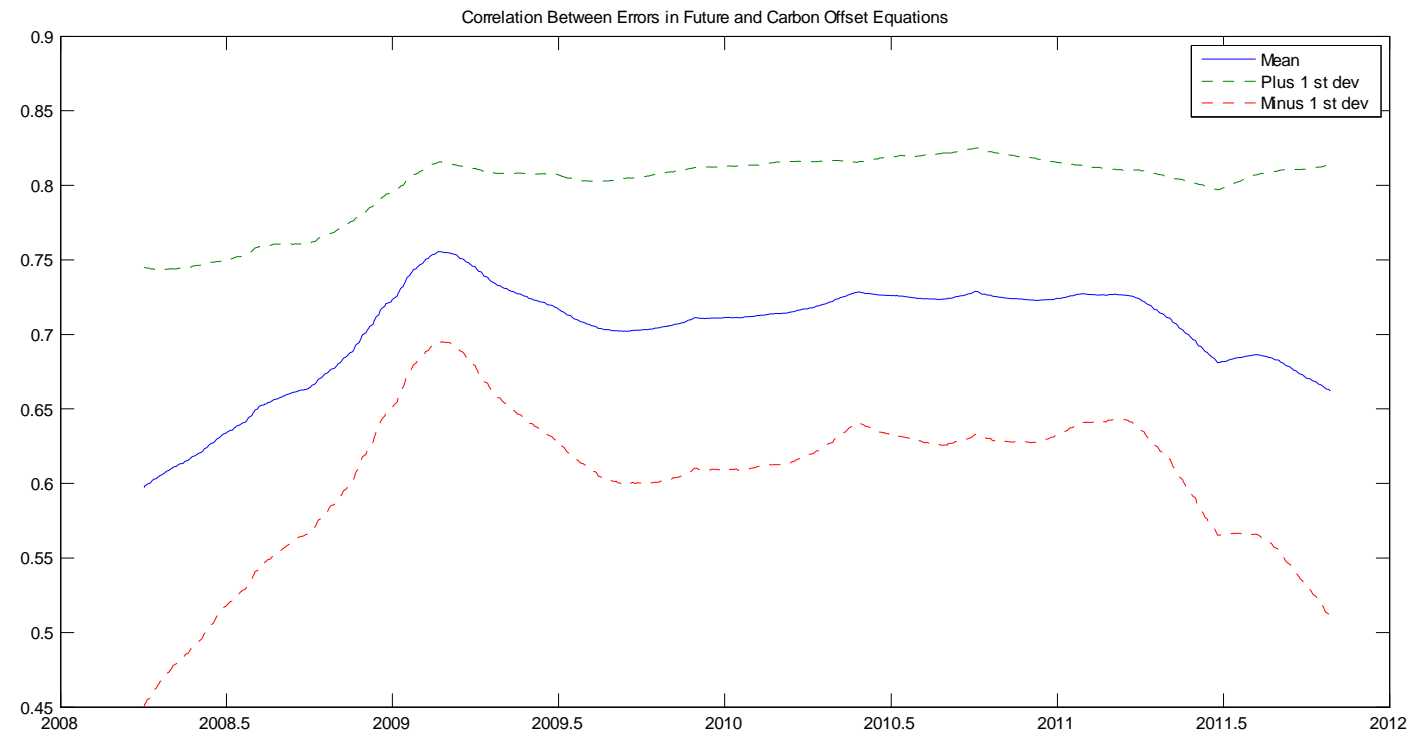

Figure 9 
We now turn to the volatilities themselves. These are plotted in Figure 10. The spot, future and offset variables all show an increase in volatility at the time of the financial crisis. But after early 2009 an interesting de-coupling occurs. The volatilities of the spot and futures variables decreases (although the volatility decrease is greater for the spot than the future). However, after a brief decrease in mid-2005, the volatility of the offset increases substantially. Presumably this is due to the unique uncertainty affecting the carbon offset market noted previously.

The correlations between the errors driving the volatilities equations (see equation 6 and note the role of $W$ as relating to volatility spillovers described in Section 3.3) are given in Table 1. The point estimates all tend to be fairly small, indicating there is a fairly low degree of correlation between the volatilities in the various markets. And they tend to be imprecisely estimated. Hence, we are not finding strong evidence of substantive volatility spillovers across markets. However, these correlations are all positive indicating that what volatility spillovers there are of the expected sign. The largest point estimate occurs for the correlation between the EUA spot and futures markets providing some weak evidence for volatility spillovers between these markets.
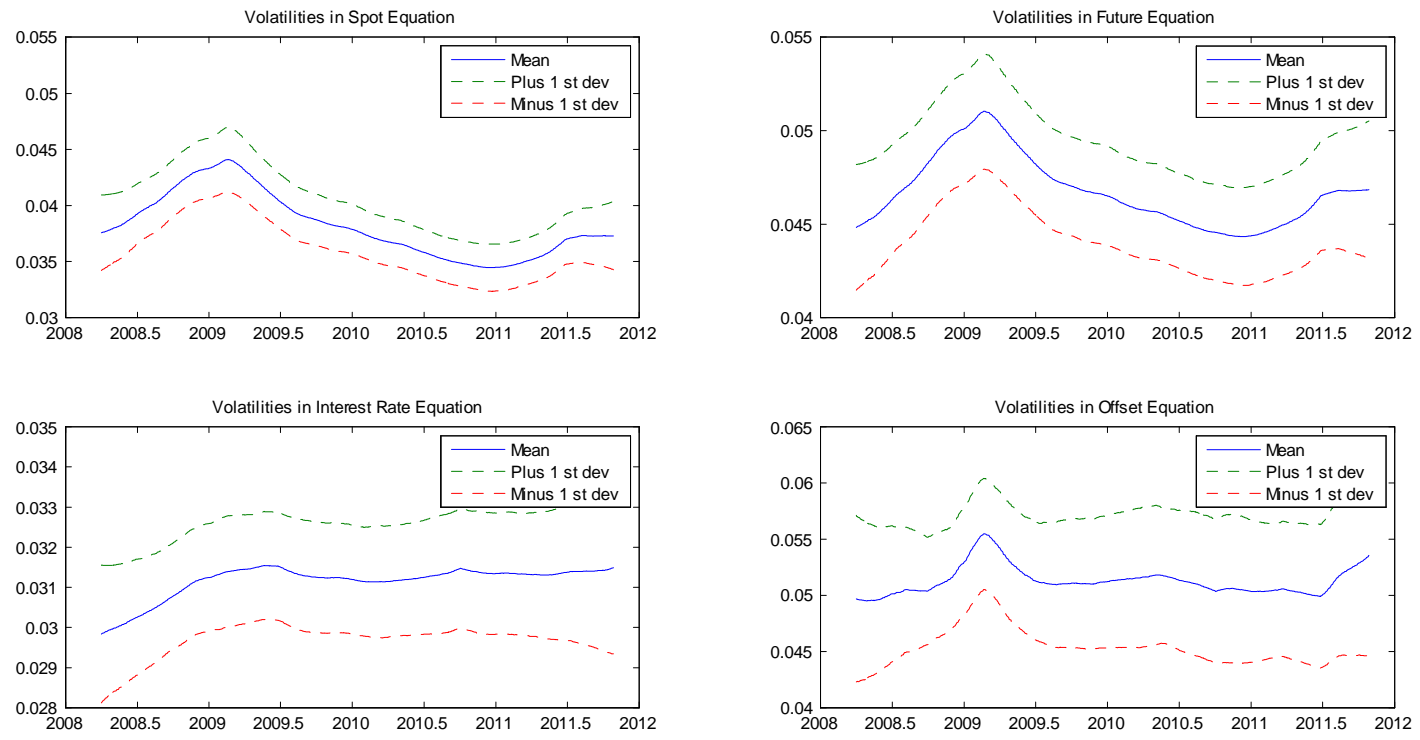

Figure 10 


\begin{tabular}{|l|l|l|l|l|}
\hline \multicolumn{6}{|c|}{ Table 1: Volatility Correlations } \\
Posterior Means (st. devs. in parentheses) & \multicolumn{1}{l|}{} \\
\hline & spot & future & interest rate & offset \\
\hline spot & 1.00 & & & \\
\hline \multirow{2}{*}{ future } & $\begin{array}{l}0.24 \\
(0.31)\end{array}$ & 1.00 & & \\
\hline \multirow{2}{*}{ interest rate } & $\begin{array}{l}0.09 \\
(0.27)\end{array}$ & $\begin{array}{l}0.06 \\
(0.29)\end{array}$ & 1.00 & \\
\hline \multirow{2}{*}{ offset } & $\begin{array}{l}0.11 \\
(0.36)\end{array}$ & $\begin{array}{l}0.05 \\
(0.34)\end{array}$ & $\begin{array}{l}0.08 \\
(0.38)\end{array}$ & \multirow{2}{*}{1.00} \\
\hline
\end{tabular}

What should a financial investor or policymaker take from our results? The main story is that there are important links between the two carbon markets we consider, but that these links are not the sort of tight and strong links that theory would typically find in financial markets. The changing institutional structures, restrictions and political uncertainties of the two markets ${ }^{12}$ mean that EUAs and CERs are not behaving as perfectly substitutable assets. Policymakers should take the message that there is some work to be done to achieve transparent markets where the rules of the game are clear. Such markets will be necessary if reductions in $\mathrm{CO}_{2}$ emissions are to be achieved in the most cost effective manner. The financial investor should take the message that political decisions are likely to have a big impact on these markets for years to come. Within this general story, we are finding that there are links between CER and EUA carbon markets and that information does flow quickly between them (i.e. our lack of evidence for Granger causality when using daily data suggests that information is flowing at a rapid rate and markets are adjusting quickly) and that the (large liquid) market for EUA futures leads the price discovery process. For policymakers interested in designing a system where carbon permits are freely and efficiently traded internationally, this is encouraging in that it suggests financial markets are potentially capable of functioning efficiently across borders. It is likely that such links will only strengthen in the future as the design of carbon markets improves and uncertainties about institutional details lessened.

\subsection{Discussion of Robustness}

It is important to investigate whether these results are robust to different model specifications. We have done so for a wide variety of specifications and the main findings outlined above occur in all of them. For the sake of brevity, the

\footnotetext{
${ }^{12}$ At the time of writing (June 2013), but subsequent to the end of our sample period, further instabilities have shaken European and US carbon markets, but in opposite directions. The European Parliaments rejection of proposals to temporarily withdraw some carbon permits from the market has led to a near collapse of prices in the EU ETS (see "The Europe's carbon market left in disarray," Financial Times, April 16, 2013). In contrast, a cut in the number of carbon permits in the Regional Greenhouse Gas Initiative (a growing carbon market involving several US states) led to an increase in carbon prices (see "Worry over scarcer credits propels US carbon market RGGI," Financial Times, June 9, 2013).
} 
empirical results have been placed in an online appendix, but we summarize the main findings here.

Working with differenced data instead of levels data has very little impact on our results. Of course, the first own lag tends to be near zero when working with differenced data (an exception is the interest rate variable), but other than that results are very similar. We obtain the same patterns in the error covariance matrix indicating that the futures market is strongly correlated with the spot and carbon offset markets (although these last two are not correlated with each other).

Working with longer lag lengths also has only a small impact on results. With extra parameters to estimate, some precision is lost, but the main results reported above are all replicated.

Similarly, if we work only with the variables implied by the cost-of-carry relationship (i.e. omit the carbon offset variable), the main results are only slightly affected. And if we work only with the bivariate TVP-VAR with the EU ETS futures price and CER offset price we find exactly the same pattern as above.

In addition, our benchmark prior uses a training sample of size 20. This is a relatively non-informative choice. But we have also also repeated the analysis with a less informative prior (training sample of size 10) and much more informative training sample of size 100. Results here, are qualitatively similar. Of most importance, results in Figures 5 through 9 are largely unchanged. For the VAR coefficients, there is less evidence of time-variation when we use the larger training sample size (since the tighter prior for $W$ expresses a belief in little time variation in coefficients). However, there is slightly more evidence of Granger causality from spot to future prices. We have also done an extensive prior sensitivity analysis to other aspects of the prior (i.e. the hyperparameters $k_{Q}, k_{C}$ and $k_{W}$ defined in the Prior Appendix at the end of this paper) and refer the reader to the results of this sensitivity analysis (and our discussion of them) in the online appendix.

Finally, it is worth mentioning that the presence of of (time-varying) cointegration would imply a restriction on our TVP-VAR in levels. This restriction would imply that the first lag of all the variables involved in any cointegrating relationship should appear in the model. Our results do not support this restriction.

\subsection{Conclusion}

TVP-VAR's with multivariate stochastic volatility allow for the flexible modelling of the conditional means, variances and covariances of multivariate time series in a time-varying fashion. We have used such methods to investigate the relationship between EU ETS spot and future prices and CER carbon offsets. With regards to Granger causality, where information from the previous day impinges on current prices, we find very little evidence for any of the variables. However, we find strong evidence of contemporaneous relationships between our three main variables. In particular, we find the EU ETS future price to be con- 
temporaneously correlated with the EU ETS future and the carbon offset (but these two latter variables are uncorrelated with each other). In light of this, we conclude that the different carbon markets are related to one another and the EU ETS future is playing the predominant role in driving the relationships. The evidence in favour of volatility spillovers from one market to another, however, is very weak. There is also some time-variation in these relationships. This time-variation is largely associated with major macroeconomic events such as the financial crisis and the European debt crisis. 


\section{References}

Alberola, E., Chevallier, J., Chèze, B. 2008a. The EU emissions trading scheme: disentangling the effects of industrial production and $\mathrm{CO}_{2}$ emissions on carbon prices. Int. Econ. 116, 93-126.

Alberola, E., Chevallier, J., Chèze, B. 2008b. Price drivers and structural breaks in European carbon prices 2005-2007. Enery Pol. 36, 787-797.

Alberola, E., Chevallier, J. Chèze, B. 2009. Emissions compliances and carbon prices under the EU ETS: A country specific analysis of industrial sectors. J. Pol. Modeling. 31, 446-462.

Alberola, E., Chevallier, J. 2009. European carbon prices and banking restrictions: evidence from Phase 1 (2005-2007). Energy J. 30, 51-80.

Baumeister, C., Durinck, E. and Peersman, G. 2008. Liquidity, inflation and asset prices in a time-varying framework for the euro area." Working Paper No. 142, National Bank of Belgium.

Bekiros, S., and Diks, C.D. 2008. The relationship between crude oil spot and futures prices: Cointegration, linear and nonlinear causality. Energy Econ. 30, 2673-2685.

Benz, E., Hengelbrock, J. 2008. Liquidity and price discovery in the European CO2 futures market: An intraday analysis. Working paper, Bonn Graduate School of Economics.

Benz, E., Truck, S. 2009. Modeling the price dynamics of CO2 emission allowances. Energy Econ. 31, 4-15.

Bolinger, M., Wiser, R. Golove, W. 2006. Accounting for fuel price risk when comparing renewable to gas-fired generation: the role of forward natural gas prices. Ener. Pol. 34, 706-720

Bredin, D. and Muckley, C., 2011. An emerging equilibrium in the EU emissions trading scheme. Energy Econ. 33, 353-362.

Caporale, G.M., Ciferri, D., Girardi, A., 2010. Time-varying spot and futures oil price dynamics. CESifo Working Paper No. 3015.

Chevallier, J., 2009. Carbon futures and macroeconomic risk factors: A view from the EU ETS. Energy Econ. 31, 614-625.

Chevallier, J., 2010a. Modelling risk premia in CO2 allowances spot and futures prices. Econ. Modelling 27, 717-729.

Chevallier, J. 2010b. A note on cointegrating and vector autoregressive relationships between $\mathrm{CO} 2$ allowances spot and futures prices. Economics Bulletin 30, 1564-1584.

Chevallier, J. 2010c. EUAs and CERs: Vector autoregression, impulse response function and cointegration analysis. Economics Bulletin, 30, 558-576.

Chevallier, J. 2011. Anticipating correlations between EUAs and CERs: a Dynamic Conditional Correlation GARCH model. Economics Bulletin, 31, $255-272$.

Chevallier, J., Ielpo, F., Mercier, L. 2009. Risk aversion and institutional information disclosure on the European carbon market: A case-study of the 2006 compliance event. Energy Pol. 37, 15-38.

Chevillon, G., Rifflart, C. 2009. Physical market determinants of the price of crude oil and the market premium. Ener. Econ. 31: 537-549. 
Chinn, M., Coibion, O., 2010. The predictive content of commodity futures. NBER working paper Working Paper 15830.

Christiansen, A., Arvanitakis, A., Tangen, K., Hasselknippe, H., 2005. Price determinants in the EU emissions trading scheme. Climate Pol. 5, 15-30.

Clark, T., Davig, T., 2008. An empirical assessment of the relationships among inflation and short- and long-term expectations. Federal Reserve Bank of Kansas City, Research Working Paper 08-05.

Cogley, T., Morozov, S., Sargent, T., 2005. Bayesian fan charts for U.K. inflation: Forecasting and sources of uncertainty in an evolving monetary system. J. Econ. Dynam. Control. 29, 1893-1925.

Cogley, T.,and Sargent, T., 2001. Evolving post World War II inflation dynamics. NBER Macroeconomics Annual. 16, 331-373.

Cogley, T. and Sargent, T., 2005. Drifts and volatilities: Monetary policies and outcomes in the post WWII U.S.. Rev. Econ. Dyn. 8, 262-302.

Convery, F., Redmond, L., 2007. Market and price developments in the European Union Emissions Trading Scheme. Rev. Environ. Econ. Policy. 1, 88-111.

D'Agostino, A., Gambetti, L., and D. Giannone. 2009. Macroeconomic forecasting and structural change. J. App. Ecm. 28, 82-101.

Daskalakis, G., Markellos, R. 2008. Are the European carbon markets efficient? Rev. Futures. Markets 17, 103-128.

Daskalakis, G., Psychoyios, D., Markellos, R. 2009. Modeling CO2 emission allowance prices and derivatives: Evidence from the European trading scheme. Journal of Banking and Finance, 33, 1230-1241.

Del Negro, M., Primiceri, G. 2013. Time varying structural vector autoregressions and monetary policy: A corrigendum. Federal Reserve Bank of New York. Staff Report 619.

Figuerola-Ferrettia, I., Gonzalez, J. 2010. Modelling and measuring price discovery in commodity markets. J. Econom. 158, 95-107.

Fezzi, C. and Bunn, D. 2009. Structural interactions of European carbon trading and energy prices. J. of Energy Markets, 2, 53-69.

Garbade, K., Silber, W. 1983. Price movement and price discovery in futures and cash markets. Rev. Econ. Stats. 65, 289-297.

Gronwald, M. and Ketterer, J. 2012. What moves the European Carbon Market? - Insights from conditional jump models. CESifo Working Paper no. 3795 .

Hasbrouck, J. (1995). One security, many markets: Determining the contributions to price discovery. J. Finance. 50, 1175-1199.

Hintermann, B., 2010. Allowance price drivers in the first phase of the EU ETS. J. Environ. Econ. Manage. 59, 43-56.

Koop, G., Korobilis, D., 2009. Bayesian multivariate time series methods for empirical macroeconomics. Found. Trends Economet. 3, 267-358.

Koop, G., Leon-Gonzalez, R., Strachan, R., 2009. On the evolution of the monetary policy transmission mechanism. J. Econ. Dynam. Cont. 33, 997-1017.

Koop, G., Tole, L., 2013. Forecasting the European carbon market. Journal of the Royal Statistical Society, Series A, 2013, 176, 723-741. 
Koop, G., Leon-Gonzalez, R., Strachan, R., 2010. Dynamic probabilities of restrictions in state space models: An application to the Phillips curve. J. Bus Econ. Stat. 28, 370-379.

Linacre, N. Kossoy, A., Ambrosi, P., 2011. State and Trends of the Carbon Market 2011. World Bank: Washington, D.C.

Longstaff, F. Wang, A. 2004. Electricity forward prices: A high-frequency empirical analysis. J. Finan.59:1877-1900.

Mansanet-Bataller, M., Chevallier, J., Hervé-Mignucci, M., Alberola, E., 2010. The EUA-sCER spread: Compliance strategies and arbitrage in the European carbon market. Mission Climat Working Paper, 2010-6. Available through the website http://www.caissedesdepots.fr.

Medina, V., Pardo, A., Pascual, R., 2011. Intraday price dynamics between EUAs and CERs in the European Carbon futures market. Available at: http://ssrn.com/abstract $=1948779$.

Milunovich, G., Joyeux, R., 2010. Market efficiency and price discovery in the EU carbon futures market. Appl. Fin. Econ. 20, 803-809.

Mizrach, B. 2012. Integration of the global carbon markets. Energy Economics 34, 2012, 335-49.

Mizrach, B. and Otsubo, Y. 2013. The market microstructure of the European Climate Exchange. Rutgers University Working Paper.

Mumtaz, H. and Surico, P. 2009. Time-varying yield curve dynamics and monetary policy. Journal of Applied Econometrics, 24, 895-913.

Nazifi, F. 2010. The price impacts of linking the European Union Emissions Trading Scheme to the Clean Development Mechanism. Environmental Economics and Policy Studies 12: 164-186.

Paolella, M, Taschini, L. 2008. An econometric analysis of emission trading allowances. Journal of Banking and Finance 32, 2022-2032.

Pindyck, R., 2001. The dynamics of commodity spot and futures markets: A primer. Energy J. 22, 1-29.

Primiceri. G., 2005. Time varying structural vector autoregressions and monetary policy. Review of Economic Studies 72, 821-852.

Rittler, D., 2012. Price discovery, causality and volatility spillovers in European Union emissions trading scheme: A high-frequency analysis. Journal of Banking and Finance, 36, 774-785.

Sims, C., 1988. Bayesian skepticism on unit root econometrics. J. Econ Dyn. Control. 12, 463-474.

TheCityUK, 2011. Carbon markets. Financial Markets Series available at www.thecityuk.com.

Trotignon, R., 2012. Combining cap-and-trade with offsets: Lessons from the EU ETS. Climate Policy, 12, 273-287.

Truck, S., Hardle, W. and Weron, R. (2012). The relationship between spot and futures CO2 emission allowance prices in the EU-ETS. Hugo Steinhaus Center Research Report HSC/12/02, Wroclaw University of Technology.

Tse, Y. 1999. Price discovery and volatility spillovers in the DJIA index and futures markets. J.Fut. Mark., 19, 911-930 
Uhrig-Homburg, M., Wagner, M. 2009. Futures price dynamics of CO2 emission certificates: An empirical analysis of the trial period. Journal of Derivatives, $17,73-88$.

Verdinelli, I., Wasserman, L. 1995. Computing Bayes factors using a generalization of the Savage-Dickey density ratio. J. Am. Stat. Assoc. 90, 614-618. 


\section{Prior Appendix}

Training sample priors are used to initialize the states in the state equations and provide priors for $Q, W$ and $C$. This is done based on OLS estimates from a constant coefficient VAR using an initial training sample of size $\tau$. Let $\widehat{\theta}_{O L S}$ and $V\left(\widehat{\theta}_{O L S}\right)$ be the OLS estimate and its covariance matrix for the VAR coefficients. Decomposing the error covariance matrix using (5) provides us with $\widehat{\sigma}_{O L S}, \widehat{A}_{O L S}$ and $V\left(\widehat{A}_{O L S}\right)$. We use the following prior

$$
\begin{gathered}
\theta_{0} \sim N\left(\widehat{\theta}_{O L S}, V\left(\widehat{\theta}_{O L S}\right)\right) \\
A_{0} \sim N\left(\widehat{A}_{O L S}, 4 \times V\left(\widehat{A}_{O L S}\right)\right) \\
\log \left(\sigma_{0}\right) \sim N\left(\log \left(\widehat{\sigma}_{0}\right), I_{3}\right) \\
Q \sim I W\left(k_{Q}^{2} \tau V\left(\widehat{\theta}_{O L S}\right), \tau\right) \\
W \sim I W\left(4 \times k_{W}^{2} I_{4}, 4\right) \\
C_{1} \sim I W\left(2 k_{C}^{2} V\left(\widehat{A}_{1, O L S}\right), 2\right) \\
C_{2} \sim I W\left(3 k_{C}^{2} V\left(\widehat{A}_{2, O L S}\right), 3\right) \\
C_{3} \sim I W\left(4 k_{C}^{2} V\left(\widehat{A}_{3, O L S}\right), 4\right)
\end{gathered}
$$

where $\widehat{A}_{1, O L S}, \widehat{A}_{2, O L S}$ and $\widehat{A}_{3, O L S}$ are the blocks of $\widehat{A}_{O L S}$ corresponding to the blocking of $C$ into $C_{1}, C_{2}$ and $C_{3}$ described in Primiceri (2005, page 825). The prior elicitation procedure for the high-dimensional TVP-VAR is now reduced to the choice of $\tau$ and the scalars $k_{Q}, k_{C}$ and $k_{W}$. We set $\tau=20$ and $k_{Q}=0.1$, $k_{C}=0.1$ and $k_{W}=0.01$, but investigate the sensitivity to these choices in the online appendix.

This is a relatively noninformative prior, centered over values implied by the training sample. For additional motivation for why this training sample prior is a sensible one see Primiceri (2005). 